\title{
Improving the population genetics toolbox for the study of the African malaria vector Anopheles nili: microsatellite mapping to chromosomes
}

Ashley Peery ${ }^{1}$, Maria V Sharakhova' ${ }^{1}$ Christophe Antonio-Nkondjio², Cyrille Ndo ${ }^{2}$, Mylene Weill3 , Frederic Simard ${ }^{4,5}$ and Igor $\vee$ Sharakhov ${ }^{1 *}$

\begin{abstract}
Background: Anopheles nili is a major vector of malaria in the humid savannas and forested areas of sub-Saharan Africa. Understanding the population genetic structure and evolutionary dynamics of this species is important for the development of an adequate and targeted malaria control strategy in Africa. Chromosomal inversions and microsatellite markers are commonly used for studying the population structure of malaria mosquitoes. Physical mapping of these markers onto the chromosomes further improves the toolbox, and allows inference on the demographic and evolutionary history of the target species.
\end{abstract}

Results: Availability of polytene chromosomes allowed us to develop a map of microsatellite markers and to study polymorphism of chromosomal inversions. Nine microsatellite markers were mapped to unique locations on all five chromosomal arms of An. nili using fluorescent in situ hybridization (FISH). Probes were obtained from 300-483 bplong inserts of plasmid clones and from 506-559 bp-long fragments amplified with primers designed using the An. nili genome assembly generated on an Illumina platform. Two additional loci were assigned to specific chromosome arms of An. nili based on in silico sequence similarity and chromosome synteny with Anopheles gambiae. Three microsatellites were mapped inside or in the vicinity of the polymorphic chromosomal inversions $2 R b$ and $2 R c$. A statistically significant departure from Hardy-Weinberg equilibrium, due to a deficit in heterozygotes at the $2 R b$ inversion, and highly significant linkage disequilibrium between the two inversions, were detected in natural An. nili populations collected from Burkina Faso.

Conclusions: Our study demonstrated that next-generation sequencing can be used to improve FISH for microsatellite mapping in species with no reference genome sequence. Physical mapping of microsatellite markers in An. nili showed that their cytological locations spanned the entire five-arm complement, allowing genome-wide inferences. The knowledge about polymorphic inversions and chromosomal locations of microsatellite markers has been useful for explaining differences in genetic variability across loci and significant differentiation observed among natural populations of An. nili.

Keywords: Chromosome inversions, genome sequence, malaria vector, microsatellite markers, population structure

\section{Background}

Anopheles gambiae, An. arabiensis, An. funestus, and $A n$. nili are the major malaria vectors in sub-Saharan Africa because they are anthropophilic and susceptible to Plasmodium falciparum [1-3]. These species belong

\footnotetext{
* Correspondence: igor@vt.edu

'Department of Entomology, Virginia Polytechnic and State University, West

Campus Drive, Blacksburg, VA 24061, USA

Full list of author information is available at the end of the article
}

to species complexes or groups, and members within these complexes/groups vary significantly in their vectorial capacity. Moreover, species can be further subdivided into populations adapted to different environments. Some malaria control initiatives have failed because they targeted the wrong species or population $[4,5]$. Understanding and targeting the heterogeneity and complexity of all major vector species and populations

\section{Biomed Central}

(c) 2011 Peery et al; licensee BioMed Central Ltd. This is an Open Access article distributed under the terms of the Creative Commons Attribution License (http://creativecommons.org/licenses/by/2.0), which permits unrestricted use, distribution, and reproduction in any medium, provided the original work is properly cited. 
is necessary for effective vector control and malaria eradication [6].

Most studies of African malaria vectors have involved only An. gambiae, An. arabiensis, and An. funestus, while research on other important malaria vectors has critically lagged behind. For An. nili, this is partly because molecular and cytogenetic tools for characterizing population structure, ecological adaptation, and taxonomic status have been lacking. Anopheles nili is widely distributed and contributes substantially to malaria transmission in the African savannah and forested areas, where it breeds in lotic streams and rivers $[7,8]$. Sporozoite rates in this species can reach $3 \%$, and the annual entomological inoculation rates can be over 100 [9]. For example, An. nili is highly anthropophagous and responsible for $10.2 \%$ of malaria transmission in the densely populated area surrounding Yaounde, the capital of Cameroon [10]. Gaps in our knowledge of this vector represent a critical barrier to progress in the field of vector biology. Recent findings of circulation of P. falciparum and other Plasmodium species in great apes and other primates [11-13] raise concerns about pathogen transfer between humans and primates, and highlight the need to improve our knowledge of malaria vectors that inhabit forested areas in Central Africa.

Multi-allelic microsatellites are informative markers for inferring the population and taxonomic status of disease vectors and parasites [1,14-26]. Microsatellites are hyper-variable markers that tend to evolve neutrally. Eleven polymorphic microsatellite markers have been developed for An. nili [27]. Recently, the level of genetic variability and differentiation has been explored among nine populations of $A n$. nili from Senegal, Ivory Coast, Burkina Faso, Nigeria, Cameroon, and The Democratic Republic of Congo (DRC) [1]. Genetic variability was determined by assessing polymorphisms at these 11 microsatellite markers, together with sequence variations in four genes within the ITS2, $28 \mathrm{~S}$ rDNA subunit D3, and mitochondrial DNA. High $F_{S T}$ estimates based on microsatellites $\left(F_{S T}>0.118, P<0.001\right)$ were observed in all comparisons between Kenge in the DRC, and all other populations sampled from Senegal to Cameroon. Sequence variation in mtDNA genes matched these results; however, low polymorphism in rDNA genes prevented detection of any population substructure at this geographical scale. Both local adaptation and geographic isolation could cause this differentiation. Geographic isolation should affect all markers, even if they are unlinked (i.e. located in different chromosomes). However, chromosomal locations of the microsatellite markers and, therefore, the degree of their physical independence in the genome were unknown. Furthermore, because reduced recombination and increased selection within or near polymorphic inversions can result in estimates of gene flow that may differ significantly from those based on loci elsewhere in the genome $[28,29]$, it would also be important to know the location of microsatellite markers with respect to polymorphic inversions in An. nili when performing population genetic analyses.

Polymorphic chromosomal inversions are usually under selection and, thus, are useful markers for studying ecological adaptations of malaria mosquitoes [30-32]. The polymorphic inversions of chromosome 2 of An. gambiae have been associated with the arid Sahel Savanna [33-37] and with tolerance to desiccation and heat $[38,39]$. Moreover, frequencies of these inversions are higher indoors where the nocturnal saturation deficit is higher than outdoors [35]. Such ecological heterogeneity has important consequences for vector control. For example, indoor residual spraying of insecticides affected only indoor populations of An. gambiae in the Garki malaria control project in Nigeria [40]. Our previous cytogenetic analysis demonstrated that two polymorphic inversions, $2 R b$ and $2 R c$, are present simultaneously in an An. nili mosquito. However, they display very different patterns of polymorphism. Frequencies of inverted and standard $2 R b$ variants were almost equal (with a deficiency of heterozygotes) in Burkina Faso, whereas only the standard arrangement was found in Cameroon. In contrast, inversion $2 R c$ occurred at higher frequency (without a deficiency of heterozygotes) in the dry savannah of Burkina Faso (83\%) and at lower frequency in the humid rainforest of Cameroon $(0.6 \%)$ [32]. Moreover, inversion $2 R c$ was found in the mountainous area (Magba), but not in the forested area (Mbebe) of Cameroon. These observations suggest the involvement of inversions in local adaptation $(2 R b)$ or in an ecogeographic adaptive cline from dry to more humid environments $(2 R c)$. Because $A n$. nili is a forestsavannah transition species, polymorphic inversions could provide genetic plasticity that allows this species to expand its range from dry savannah to deforested areas of Central Africa, where most of the human population is present. The relationship between these two inversions has not been studied. For example, it would be useful to know if inversions $2 R b$ and $2 R c$ are in linkage disequilibrium (LD) in natural populations of $A n$. nili.

In this study, we mapped nine microsatellite markers to polytene chromosomes of An. nili using fluorescent in situ hybridization (FISH). Plasmid clones of the An. nili microsatellites and/or ad hoc DNA fragments amplified from a low coverage assembly of the An. nili genome were used as probes. The microsatellites hybridized to unique locations on all chromosomes both inside and outside polymorphic inversions. We further 
demonstrated highly significant linkage disequilibrium between inversions $2 R b$ and $2 R c$. This knowledge about polymorphic inversions and chromosomal locations of microsatellite loci helped us to better understand genetic variations and differentiation in natural populations of An. nili.

\section{Results}

\section{Experimental approaches to microsatellite mapping}

In the current study, we used three experimental approaches to map microsatellite markers to the polytene chromosomes from ovarian nurse cells of wild female $A n$. nili specimens collected in Burkina Faso. In the first approach, microsatellites were amplified from genomic DNA using specific primers, which were previously developed [27]. All microsatellites were successfully amplified from the genomic DNA. However, because of the small size of the products (approximately 90-230 bp), a majority of the probes failed to hybridize to chromosomes. Only one microsatellite, 1F43, was mapped by this method. In the second approach, inserts containing microsatellites previously cloned in the pUC18 plasmid [27] were amplified using M13 forward and reverse primers. The insert sizes in this case ranged from 300 to $483 \mathrm{bp}$. Most of the microsatellites, except F41, B115, 2C157, and A154 were successfully labeled and hybridized to polytene chromosomes. Marker 1F43 was also mapped by the second approach to the same chromosomal region as in the first approach. In the third approach, we used a recently obtained genomic sequence assembly of $A n$. nili to identify the microsatellite loci via BLASTN search and to design primers for PCR. These primers allowed the amplification of 506559 bp-long PCR products containing the microsatellites that could not be hybridized previously. The An. nili genome was sequenced by Illumina 72 bp paired-end method using genomic DNA isolated from two individual larvae collected in Dinderesso, Burkina Faso. The assembly consisted of 51,048 contigs with a total length of $98,320,874 \mathrm{bp}$. The average contig length was 1,926 bp and the maximum contig length was 30,512 bp. Primers were designed for microsatellites B115, 2C157, and A154 (accession numbers: JF742787, JF742788, JF742789) based on sequences identified by BLASTN (Table 1). We successfully mapped microsatellites B115 and $2 \mathrm{C} 157$ to polytene chromosomes using this approach. However, microsatellite A154 failed to hybridize to chromosomes despite several attempts. The BLASTN search yielded multiple hits for microsatellite locus F41 in the An. nili genome because of widespread occurrence of the $(\mathrm{CT})_{11} \mathrm{TT}(\mathrm{CT})_{8}$ repeats. The BLASTN search of the flanking regions did not yield any significant hits in the An. nili genome.

\section{Locations of microsatellite markers on the chromosomal map of Anopheles nili}

The An. nili chromosomal complement in ovarian nurse cells consists of five chromosomal arms: X, 2R, $2 \mathrm{~L}, 3 \mathrm{R}$ and $3 \mathrm{~L}$. All nine microsatellites were mapped to unique locations on all autosomes and the $\mathrm{X}$ chromosome using FISH (Figure 1). We assigned these microsatellites to the precise positions on the recently developed polytene chromosome map of An. nili (Figure 2, Table 2). Two microsatellites hybridized to the $\mathrm{X}$ chromosome in subdivisions $2 \mathrm{~A}$ and $3 \mathrm{~A}$; three microsatellites localized to the $2 \mathrm{R}$ arm in subdivisions $15 \mathrm{C}, 17 \mathrm{AB}$ and $18 \mathrm{~A}$; two microsatellites were mapped to the $3 \mathrm{~L}$ arm in regions $38 \mathrm{~B}$ and $44 \mathrm{~A}$; and arms $2 \mathrm{~L}$ and $3 \mathrm{R}$ each hybridized with only one microsatellite marker in sections $20 \mathrm{C}$ and $31 \mathrm{C}$, respectively. Only one microsatellite, 2C157, was mapped inside the previously described polymorphic inversion $2 R c$. Microsatellite 1A27 localized to subdivision 15C located between inversions $2 R b$ and $2 R c$. Microsatellite $1 F 43$ was mapped to subdivision $18 \mathrm{~A}$ located next to the proximal breakpoint of inversion $2 R c$.

\section{Microsatellite mapping through comparative genomics with Anopheles gambiae}

In this study, we identified sequences in the An. gambiae genome that are homologous to six microsatellite loci of An. nili (Table 2). The remaining five loci did not have significantly similar sequences in the An. gambiae genome. Markers A14, 2C157, 2Ateta, and B115, which we mapped in $A n$. nili by FISH, were placed to specific regions of homologous chromosome arms in An. gambiae by BLASTN. The BLASTN results confirmed arm homologies between the two species that we determined in our previous study [32]. In addition, we mapped in silico microsatellites A154 and F41, which were not previously mapped by FISH. We used the Illumina-based genome sequence assembly of $A n$. nili for A154 and the clone sequence for F41 to perform BLASTN against the An. gambiae genome. According to

Table 1 Primers designed for the microsatellite loci using the An. nili genome sequence.

\begin{tabular}{llll}
\hline Locus & Forward primer & Reverse primer & Size of PCR product \\
\hline B115 & CACGCTGGCTAAGAGGAAAC & CTGGTCTCTAGCACCCGAAG & $559 \mathrm{bp}$ \\
$2 \mathrm{C} 157$ & GAGAGCGGCTGTTCGTAATC & CGGACTGGCGAAATAAACAT & $506 \mathrm{bp}$ \\
A154 & CACAGGGACGCCTAAAACAT & GACCCGCGTAACTAGGGAAT & $537 \mathrm{bp}$ \\
\hline
\end{tabular}




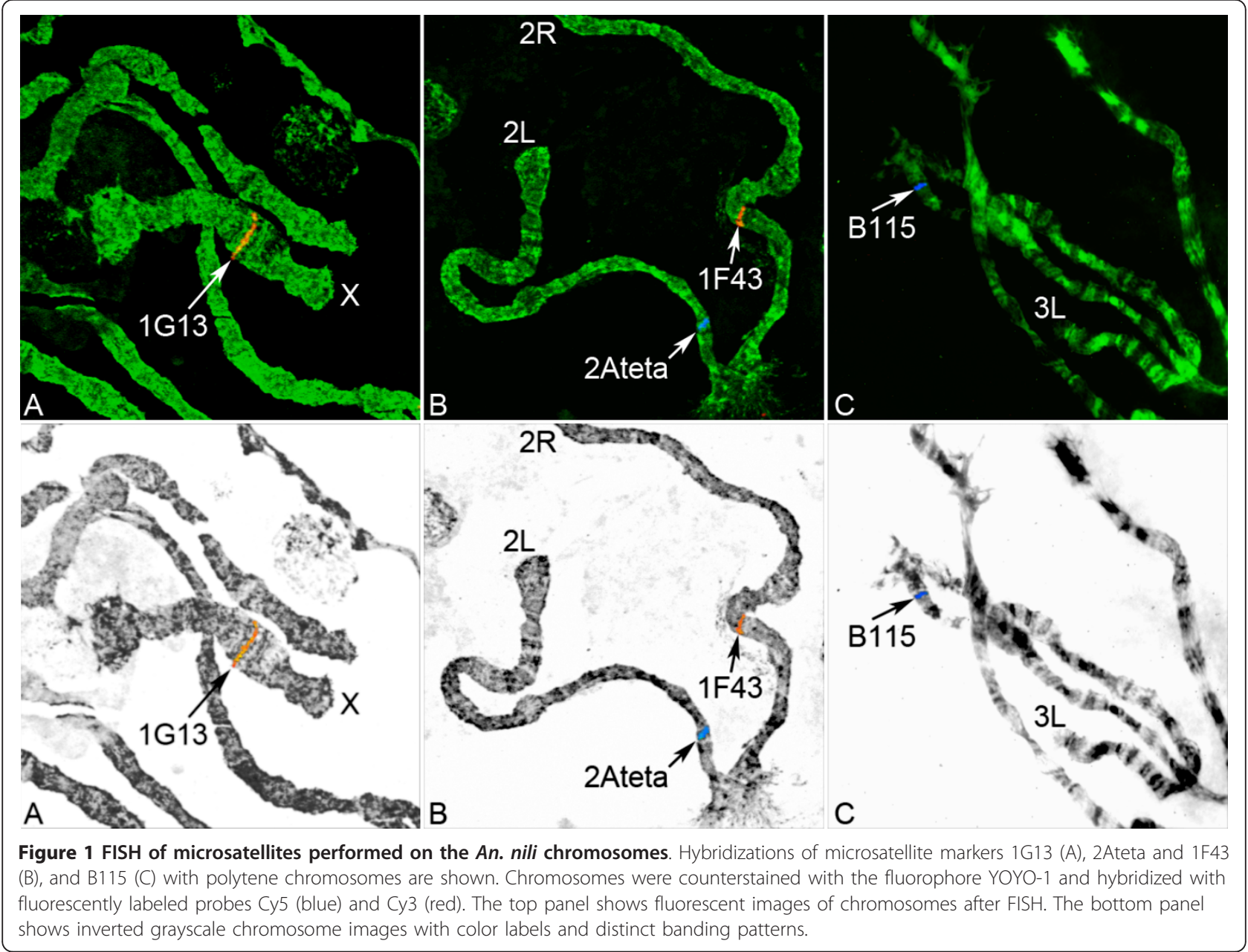

the established arm homology, we assigned microsatellites A154 and F41 to 3R and 2R chromosome arms of An. nili, respectively (Table 2).

\section{Inversion polymorphism in Anopheles nili}

To test if inversions $2 R b$ and $2 R c$ are in LD, we karyotyped 44 An. nili females collected in Dinderesso, Burkina Faso. Inversion frequencies were calculated jointly for these individuals and for 56 previously karyotyped females from the same village [32]. We found a highly significant LD between the two inversions ( $P=0.00054)$, i.e., these inversions occur together much more often than expected. Frequencies of inverted and standard $2 R b$ variants were almost equal ( 0.51 and 0.49 for the standard and inverted arrangement, respectively). However, a highly significant departure from Hardy-Weinberg proportions due to a deficit in heterozygotes (e.g., positive $F_{I S}$ value) was observed at this locus $\left(F_{I S}=+0.603, \mathrm{P}<0.0001\right.$ single test level). Inversion $2 R c$ occurred at high frequency in the sample (0.825), with no significant deviation from Hardy-Weinberg equilibrium (HWE) $(\mathrm{P}=0.49)$ (Table 3$)$.

\section{Discussion}

Availability of readable polytene chromosomes in $A n$. nili allowed us to develop a map of microsatellite markers and to study polymorphism of chromosomal inversions. Among the three experimental approaches used to map microsatellite markers to chromosomes, using cloned inserts and genome sequence assembly of $A n$. nili to amplify and hybridize microsatellites was more successful than using microsatellite fragments amplified with primers for population genetics studies [1,27] (Figure 1). Larger DNA fragments were more suitable for effective labeling by the random primer method than smaller fragments obtained with primers for population genetic studies [27]. In addition to these experimental approaches, we conducted BLASTN searches of the $A n$. nili genome fragments with microsatellites (both Illumina generated and cloned) against the An. gambiae genome to assign microsatellite loci to chromosome arms according to the synteny between $A n$. nili and $A n$. gambiae [32] (Table 2). Although, X, 2R, and 3R are homologous between the two species, the $2 \mathrm{~L}$ arm of $A n$. 


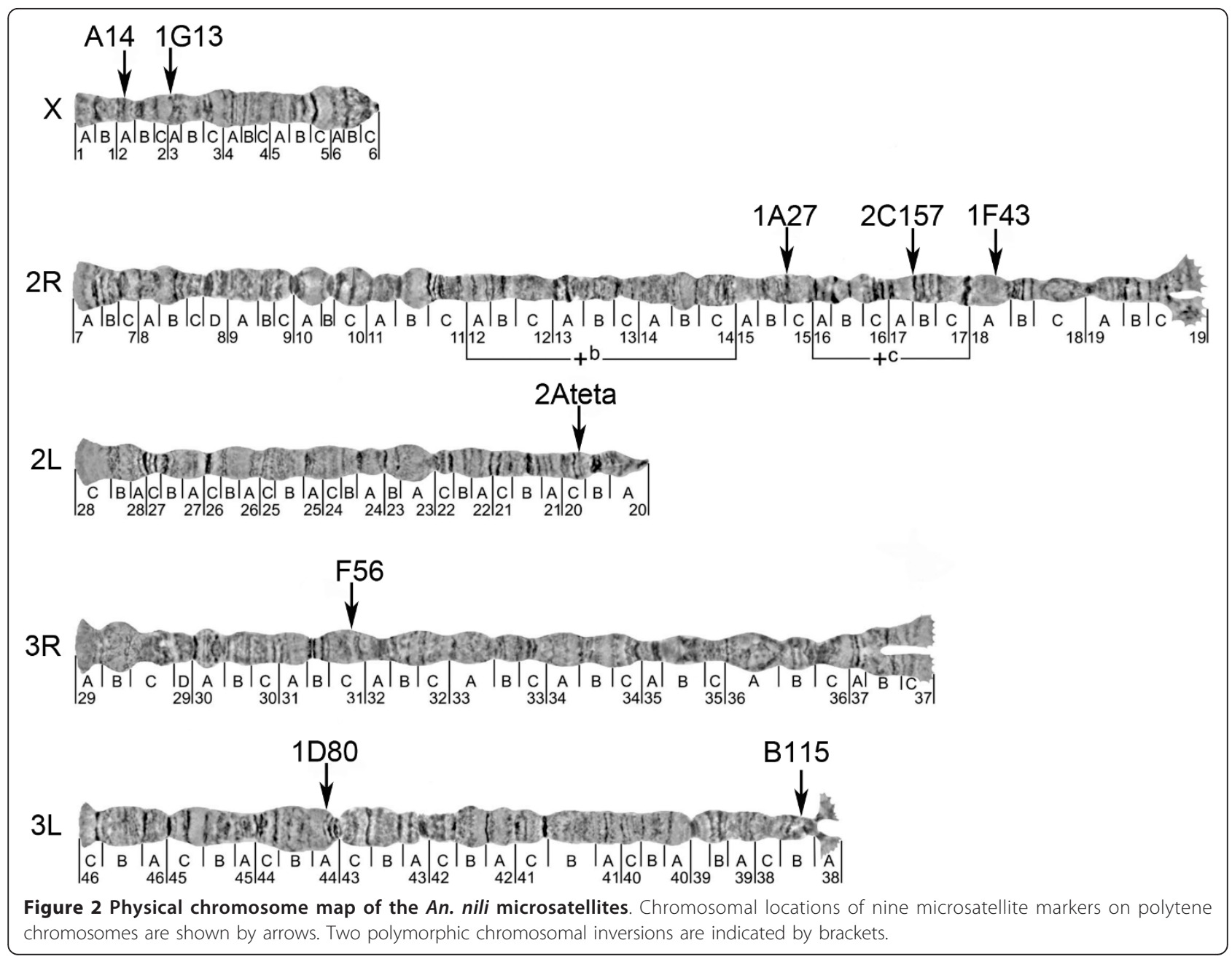

gambiae corresponds to the $3 \mathrm{~L}$ arm of An. nili, and the $3 \mathrm{~L}$ arm of An. gambiae corresponds to the $2 \mathrm{~L}$ arm of $A n$. nili, indicating the presence of a whole-arm translocation. Because of the high number of inversions fixed between the two species, the genome of An. gambiae cannot be used as a reference for precise positioning of microsatellites on the An. nili chromosomes. In our previous study, we calculated the minimum number of

Table 2 Location of the An. nili microsatellite markers on polytene chromosomes.

\begin{tabular}{|c|c|c|c|c|c|}
\hline & Locus & Accession number ${ }^{a}$ (with length) & $\begin{array}{l}\text { Location on the An. nili } \\
\text { map }\end{array}$ & $\begin{array}{l}\text { Location on the An. gambiae } \\
\text { map }\end{array}$ & $\begin{array}{l}\text { Best e-value for } \\
\text { BLASTN }\end{array}$ \\
\hline 1. & A14 & AJ536274 (467 bp) & $X: 2 A$ & $x: 3 D$ & $3 e-08$ \\
\hline 2. & $1 \mathrm{G} 13$ & AJ536271 (441 bp) & $X: 3 A$ & - & - \\
\hline 3. & $1 \mathrm{~A} 27$ & AJ536268 (300 bp) & 2R: $15 \mathrm{C}$ & - & - \\
\hline 4. & 2C157 & AJ536273 (404 bp) JF742788 (2,967bp) & $2 R: 17 A B$ & $2 \mathrm{R}: 10 \mathrm{~A}$ & 7e-04 \\
\hline 5. & $1 F 43$ & AJ536270 (462 bp) & $2 \mathrm{R}: 18 \mathrm{~A}$ & - & - \\
\hline 6. & F41 & AJ536277 (423 bp) & 2R: unknown ${ }^{b}$ & $2 R: 16 D$ & $2 \mathrm{e}-27$ \\
\hline 7. & 2Ateta & AJ536272 (479 bp) & 2L: $20 \mathrm{C}$ & $3 \mathrm{~L}: 45 \mathrm{~A}$ & $3 e-17$ \\
\hline 8. & F56 & AJ536278 (474 bp) & $3 R: 31 C$ & - & - \\
\hline 9. & A154 & JF742789 (1,522 bp) & 3R: unknown ${ }^{b}$ & $3 R: 30 E$ & $6 e-43$ \\
\hline 10. & B115 & $\begin{array}{l}\text { AJ536276 (350 bp) JF742787 (10,057 } \\
\text { bp) }\end{array}$ & 3L: 38B & $2 \mathrm{~L}: 20 \mathrm{D}$ & $3 e-24$ \\
\hline 11. & $1 \mathrm{D} 80$ & AJ536269 (483 bp) & $3 \mathrm{~L}: 44 \mathrm{~A}$ & - & - \\
\hline
\end{tabular}

${ }^{a}$ AJ refers to clone sequences; JF refers to assembled sequences.

${ }^{b}$ Arms determined based on the chromosome homology established earlier [19].

"-" no homologous sequence found in the An. gambiae genome using BLASTN. 
Table 3 Chromosome inversion polymorphism in the An. nili population from Dinderesso, Burkina Faso.

\begin{tabular}{lll}
\hline & $\mathbf{2 R \boldsymbol { b }}$ & $\mathbf{2 R \boldsymbol { c }}$ \\
\hline Inversion frequency & 0.490 & 0.825 \\
$\boldsymbol{F}_{/ S}{ }^{\mathrm{a}}$ & +0.603 & +0.070 \\
$\mathrm{P}(\mathrm{HW})^{\mathrm{b}}$ & $<0.0001$ & 0.49 \\
\hline
\end{tabular}

${ }^{\mathrm{a}} F_{\text {IS }}$ was computed as in [59].

${ }^{b}$ Exact test for conformance to Hardy-Weinberg equilibrium, as implemented in the software in GENEPOP V4.0 [58].

fixed inversions among An. nili, An. gambiae, and $A n$. stephensi and concluded that $A n$. nili is, at least, as diverged from $A n$. gambiae as $A n$. stephensi [32]. In addition to the fixed inversion differences, $A n$. nili has a distinct pattern of polymorphic inversions. Therefore, the chromosomal positions of homologous loci with respect to polymorphic inversions will be different in the two species.

The developed microsatellite map (Figure 2) improved our understanding of the population genetic structure of An. nili. A recent study using 11 microsatellite markers demonstrated significant genetic differentiation of the An. nili population of Kenge in the DRC as compared to the An. nili populations in Central and West Africa [1]. Both local adaptation and geographic isolation could cause this differentiation. Extensive allele sharing between populations and homogeneity across loci suggested that enhanced genetic drift rather than selection was responsible for the observed pattern. Although it is unlikely that all loci would be within or close to the same inversion, chromosomal mapping of the markers was needed to determine the degree of their independence. Our study demonstrated that the microsatellite locations are not limited to one or a few specific regions in the genome but spanned the entire five-arm complement (Figure 2). Because most of these markers are physically unlinked, we conclude that enhanced genetic drift, rather than selection was responsible for reduced variability and increased differentiation of the Kenge, DRC population (see also Additional file 1). These data strongly suggest the role of the equatorial forest block as a barrier to gene flow between the south-African and north-African populations of An. nili.

Among the mapped microsatellite loci, 1A27 and A14 were found to be in particularly strong and significant departure from HWE due to a deficiency of heterozygotes in West Africa (Burkina Faso and Senegal) but not in Central Africa (Cameroon) [1]. We also detected a highly statistically significant departure from HWE due to a deficit in heterozygotes $\left(F_{I S}=+0.603, \mathrm{P}<0.0001\right.$ single test level, Table 3 ) at inversion $2 R b$ in the village of Dinderesso in Burkina Faso among 100 karyotyped females. It is possible that the $2 R b$ inversion plays a role in local adaptation and subdivides $A n$. nili into populations with limited gene flow. This process or the presence of null alleles could cause heterozygote deficiency at microsatellite loci. In contrast, inversion $2 R c$ demonstrated no significant deviation from HWE (Table 3 ). However, we found a highly significant LD between the two inversions ( $\mathrm{P}=0.00054)$. Microsatellite $1 \mathrm{~A} 27$ is located between $2 R b$ and $2 R c$ and it could be affected by the LD and reduced recombination in the vicinity of chromosomal breakpoints (Figure 2). Future studies should determine whether this LD is caused by physical linkage or selection. $2 \mathrm{C} 157$ is the only microsatellite located inside an inversion; and it does not demonstrate deficiency of heterozygotes. This locus is in the middle of inversion $2 R c$ where recombination could be close to normal. Moreover, significant departure from HWE due to a deficiency of heterozygotes was demonstrated for inversion $2 R b$ but not for $2 R c$. Marker A14 is located on the $\mathrm{X}$ chromosome, which lacks polymorphic inversions, suggesting that genetic differentiation is not limited to the inversions (see Additional file 1 for locus-specific $F_{S T}$ estimates). Microsatellites in Hardy-Weinberg disequilibrium could also be associated with genes responsible for epidemiologically important ecological adaptations. Indeed, the microsatellite motif of A14 is located 259 bp upstream from the start codon of an open reading frame in the $A n$. nili genome, and the sequence homologous to the A14 clone is found in the 5'UTR and the first exon of the $A n$. gambiae gene AGAP000275. According to gene ontology annotation, the protein encoded by this gene has oxidoreductase activity. The transcript of AGAP000275 has demonstrated significant differential expression in a variety of mosquito tissues and life stages. Significant differences have been shown between: different stages of embryonic development, between embryonic serosa and embryo [41], between blood-fed and non-blood-fed females, between fat body and ovaries, between males and females, between adults and larva [42], between hemolymph and carcass [43], between West and East African strains of S form gravid females [44], between larval anterior midgut and hindgut [45], between larval salivary gland and whole organism [46]. Significant 1.2-fold increase in the transcription level of AGAP000275 has also been found between females 6 hours and 24 hours after mating [47]. Altogether, these data suggest strong selection acting on AGAP000275 in An. gambiae that might translate into non-neutral polymorphism distribution at locus A14 in An. nili. Sequences homologous to other An. nili microsatellite loci with significant BLASTN hits in the An. gambiae genome were found outside genes, except microsatellite B115, which was located within the second intron of gene AGAP004824.

Our recent mapping of 12 microsatellites to An. stephensi chromosomes has demonstrated that the 
chromosomal position of microsatellites may affect estimates of population genetic parameters [48]. In a similar study of An. funestus, 16 microsatellites were physically mapped to polytene chromosomes, and the location of microsatellites based on the inversions were determined [49]. Interestingly, microsatellites located between inversions $3 R a$ and $3 R b$ in $A n$. funestus were found in LD with these inversions in Burkina Faso [50] but not in Cameroon [30], reflecting different evolutionary outcomes in different eco-geographic regions. Altogether, these studies point to the importance of physical mapping of molecular markers exposed to contrasted evolutionary dynamics for unravelling the demographic and evolutionary history of malaria vectors. This paper provides the necessary toolbox for such endeavour to be pursued in An. nili.

\section{Conclusions}

Our study demonstrates that the chromosomal position of microsatellites is informative for interpretation of population genetics data and highlights the importance of developing physical maps for nonmodel organisms. Next-generation sequencing can be used for designing microsatellite primers to obtain longer microsatellitecontaining probes and improve FISH mapping. An Illumina-based genome sequence assembly can also be used for identifying homologous loci in the reference genomes and assigning microsatellite markers to chromosomal arms in a species of interest based on synteny. The integrated chromosomal map of microsatellites and inversions will allow for more complete characterization of $A n$. nili in future population genetics studies. It will be possible to test for a LD among and between inversions and microsatellites, genetic differentiation at microsatellite loci located inside and outside inversions, and genetic differentiation according to the distance from inversion breakpoints. In addition, the new genetic map could be used for designing quantitative trait loci mapping studies for this species.

\section{Methods}

Wild mosquito collection, preservation, and species identification

Anopheles nili adult females were collected by pyrethrum spraying and bednet traps in the village of Dinderesso $\left(11^{\circ} 14^{\prime} \mathrm{N} ; 4^{\circ} 23^{\prime} \mathrm{W}\right)$ in Burkina Faso. Anopheles nili larvae were collected in a river in Dinderesso, Burkina Faso. Specimens were identified in the field as members of the $A n$. nili group by using morphological identification keys [51-53] and were further characterized by molecular assays as An. nili s.s. [54]. Females were dissected under a microscope, and their ovaries at the appropriate stage were preserved in Carnoy's fixative solution ( 3 parts of ethanol: 1 part of glacial acetic acid by volume). Ovaries were kept at room temperature overnight before being stored at $-20^{\circ} \mathrm{C}$. Larvae were preserved in Carnoy's fixative solution and stored at $-20^{\circ} \mathrm{C}$.

\section{Genome sequencing and BLASTN}

The genome assembly for $A n$. nili was obtained by sequencing of genomic DNA isolated from two larvae collected in Dinderesso, Burkina Faso. Genomic DNA was isolated using the Qiagen DNeasy Blood and Tissue Kit (Qiagen Science, Germantown, MD, USA). The library preparation and sequencing was performed on the Illumina Genome Analyzer IIx, using 72 bp pairedend processing at Ambry Genetics Corp. (Aliso Viejo, CA, USA). Samples were prepared using the Illumina protocol outlined in "Preparing Samples for Sequencing Genomic DNA” (Part \# 11251892 Rev. A 2007). Briefly, DNA fragment ends were repaired and phosphorylated using Klenow, T4 DNA Polymerase and T4 Polynucleotide Kinase. Next, an 'A' base was added to the 3' end of the blunted fragments, followed by ligation of Illumina paired-end adaptor via T-A mediated ligation. The ligated products were size selected by gel purification and then PCR amplified using Illumina Paired-End primers. The library size and concentration were determined using an Agilent Bioanalyzer. The library was seeded onto the flowcell at $8 \mathrm{pM}$, yielding approximately $275 \mathrm{~K}$ clusters per tile, and it was sequenced using 73 cycles of chemistry and imaging (73 cycles) for read 1 and read 2. Initial data processing, including extraction of cluster intensities and base calling, was done using RTA 1.6.47 (SCS version 2.6.26). Sequence quality filtering scripts were executed in the Illumina CASAVA software (ver 1.6.0, Illumina, Hayward, CA). Quality metric data included the approximate proportion of sequences with 1, 2, 3 or 4 errors, IVC plots, and visualizations of cluster intensity over the duration of the sequencing run. The BLASTN algorithm was used to identify homologous sequences in the An. gambiae genome, which is available at VectorBase [55]. The BLASTN algorithm was also used to find larger genomic fragments with microsatellite loci in the An. nili genome using a server and the Geneious 5.1.5 software http://www.geneious. com, a bioinformatics desktop software package produced by Biomatters Ltd http://www.biomatters.com.

\section{Probe preparation}

Three approaches were utilized for the microsatellite probe preparation. First, microsatellites were directly amplified from the An. nili genomic DNA using previously designed primers [27]. Approximately 90-230 bp-long fragments were amplified. Second, plasmid clones with microsatellites were used as templates for insert amplification. In this case, 300-483 bp-long fragments were amplified from the pUC18 plasmid DNA 
using standard M13 forward and reverse primers (Fermentas, Inc., Glen Burnie, MD, USA). Third, primers were designed for three microsatellites using the Primer3 program [56] based on sequences identified by BLASTN in the genome assembly of An. nili (accession numbers: JF742787, JF742788, JF742789). The size of these fragments was about 506-559 bp. PCR conditions were as follows: $94^{\circ} \mathrm{C}$ for $5 \mathrm{~min}$; 45 cycles of $94^{\circ} \mathrm{C}$ for 45 s, $50^{\circ} \mathrm{C}$ for $45 \mathrm{~s}$ and $72^{\circ} \mathrm{C}$ for $30 \mathrm{~s}$; and $72^{\circ} \mathrm{C}$ for $5 \mathrm{~min}$. DNA was purified using the GE healthcare illustra GFX PCR DNA and Gel Band Purification Kit (GE Healthcare UK Ltd, Buckinghamshire, UK). Probes were labeled using Cy3-AP3-dUTP or Cy5-AP3-dUTP (GE Healthcare UK Ltd., Buckinghmashire, UK) fluorophores by a Random Primer DNA Labelling System (Invitrogen Corporation, Carlsbad, CA, USA).

\section{Chromosome preparation and FISH}

To obtain chromosomal slides, follicles of ovaries were separated in $50 \%$ propionic acid. Then a cover slip was used to squash the follicles. The quality of slides and the banding pattern of polytene chromosomes were analyzed using an Olympus CX-41 phase contrast microscope (Olympus America Inc., Melville, NY, USA). Slides then were dipped into liquid nitrogen, cover slips were removed, and slides were dehydrated in 50\%, 70\%, $90 \%$ and $100 \%$ ethanol. Slides were air dried and used for further experiments. Labelled probes were hybridized at $42^{\circ} \mathrm{C}$ to $\mathrm{An}$. nili polytene chromosome slides overnight. Then, slides were washed in $0.2 \mathrm{X}$ SSC (Saline Sodium citrate, $0.03 \mathrm{M}$ sodium chloride and $0.03 \mathrm{M}$ sodium citrate) at $42^{\circ} \mathrm{C}$ and room temperature. Chromosomes were stained using YOYO-1 (Invitrogen Corporation, Carlsbad, CA, USA), and slides were mounted in 1,4-diazabicyclo[2.2.2] octane (DABCO) antifade solution. A Zeiss LSM 510 Laser Scanning Microscope (Carl Zeiss MicroImaging, Inc., Thornwood, NY, USA) was used to detect fluorescent signals. Microscopic images were taken from the signal, and the locations of signals were determined using a standard cytogenetic photo map of An. nili [32].

\section{Image processing}

Confocal images were processed using Image and Adobe Photoshop software as described elsewhere [57]. Briefly, color channels were split from the initial RGB image into separate images. Each channel image was converted into the monochrome image by using a 'Channel mixer' and then inverted. The inverted monochrome image was adjusted by using a 'Curves' tool until the background is removed and each chromosome of the spread becomes fuzzy-edged. The reduction of noise was achieved by blurring of each pixel with the Gaussian blur filter tool. The quality of the image was improved by additional application of the 'Curves' and/or subtraction of the 'Relative white'. Finally, green channel image with chromosomes was merged with monochrome image FISH signals. Processing yielded contrasted, inverted, grayscale images with color labels, which are more suitable for mapping.

\section{Population genetics analyses}

Homozygous and heterozygous inversions were scored using the chromosomal map published earlier [32]. Alternative chromosomal arrangements were considered as different alleles of the same locus, and conformance to Hardy-Weinberg equilibrium was tested with Fisher's exact tests available in GENEPOP V4.0 [58]. A $F_{I S}$ value was computed as in [59]. LD between the inversions $2 R b$ and $2 R c$ was assessed using the log likelihood ratio statistic (G-test) available in GENEPOP V4.0 [58].

\section{Additional material}

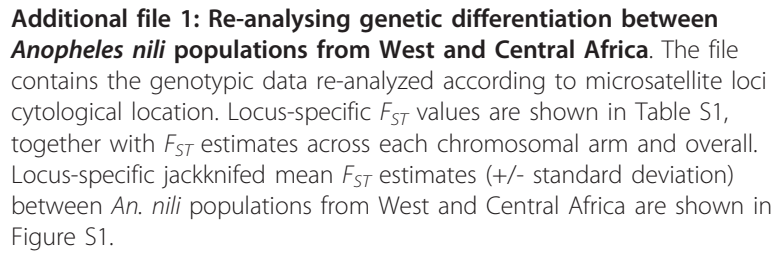

\section{List of abbreviations}

BLASTN: Basic Local Alignment Search Tool for Nucleotide sequences; DABCO: 1,4-diazabicyclo [2.2.2] octane; FISH: fluorescent in situ hybridization; HWE: Hardy-Weinberg equilibrium; LD: linkage disequilibrium.

\section{Acknowledgements}

We are grateful to Z. Tu for hosting the genome sequence of An. nili on his server and conducting BLASTN. We thank S. Demin for explaining the image processing procedure. This work was supported by the National Institute of Allergy and Infectious Diseases, National Institutes of Health (grant R21AI079350 to IVS).

\section{Author details}

${ }^{1}$ Department of Entomology, Virginia Polytechnic and State University, West Campus Drive, Blacksburg, VA 24061, USA. ${ }^{2}$ Malaria Research Laboratory, Organisation de Coordination pour la lutte contre les Endémies en Afrique Centrale (OCEAC), Yaounde, BP 288, Cameroon. ${ }^{3}$ Institut des Sciences de l'Evolution, Université Montpellier 2, Centre National de la Recherche Scientifique, Place Eugène Bataillon, C.C. 065, 34095 Montpellier, France. ${ }^{4}$ Unité Mixte de Recherche 224 'Maladies Infectieuses et Vecteurs: Ecologie, Genetique, Evolution et Controle (MIVEGEC)', Team 'Biology, Ecology and Evolution of vector Systems (BEES)', Institut de Recherche pour le Developpement (IRD), BP 64501, Montpellier 34394, France. ${ }^{5}$ Institut de Recherche en Sciences de la Santé (IRSS), 399 Avenue de la Liberte, Bobo Dioulasso, 01BP171, Burkina Faso.

\section{Authors' contributions}

IVS designed research; AP, IVS, and MVS performed karyotyping and physical mapping; CAN and CN conducted field work and mosquito identification FS, MVS, and IVS analyzed data; MW prepared plasmid DNA; AP and IVS prepared genomic DNA for sequencing; IVS performed BLASTN searches using VectorBase and a Geneious software; AP and IVS wrote the paper, 
which was critically revised by CAN, FS, and MVS. All authors read and approved the final manuscript.

\section{Competing interests}

The authors declare that they have no competing interests.

Received: 5 August 2011 Accepted: 19 October 2011

Published: 19 October 2011

\section{References}

1. Ndo C, Antonio-Nkondjio C, Cohuet A, Ayala D, Kengne P, Morlais I, Awono-Ambene PH, Couret D, Ngassam P, Fontenille D, Simard F: Population genetic structure of the malaria vector Anopheles nili in subSaharan Africa. Malar J 2010, 9:161

2. Antonio-Nkondjio C, Kerah CH, Simard F, Awono-Ambene P, Chouaibou M, Tchuinkam T, Fontenille D: Complexity of the malaria vectorial system in Cameroon: contribution of secondary vectors to malaria transmission. J Med Entomol 2006, 43:1215-1221.

3. Okara RM, Sinka ME, Minakawa N, Mbogo CM, Hay SI, Snow RW: Distribution of the main malaria vectors in Kenya. Malar J 2010, 9:69.

4. Van Bortel W, Harbach RE, Trung HD, Roelants P, Backeljau T, Coosemans M: Confirmation of Anopheles varuna in Vietnam, previously misidentified and mistargeted as the malaria vector Anopheles minimus. Am J Trop Med Hyg 2001, 65:729-732.

5. Coluzzi M: Malaria vector analysis and control. Parasitol Today 1992, 8:113-118

6. Enayati A, Hemingway J: Malaria Management: Past, Present, and Future. Annual Review of Entomology 2010, 55:569-591.

7. Sinka ME, Bangs MJ, Manguin S, Coetzee M, Mbogo CM, Hemingway J, Patil AP, Temperley WH, Gething PW, Kabaria CW, et al: The dominant Anopheles vectors of human malaria in Africa, Europe and the Middle East: occurrence data, distribution maps and bionomic precis. Parasit Vectors 2010, 3:117.

8. Djenontin A, Bio-Bangana S, Moiroux N, Henry MC, Bousari O, Chabi J, Osse R, Koudenoukpo S, Corbel V, Akogbeto M, Chandre F: Culicidae diversity, malaria transmission and insecticide resistance alleles in malaria vectors in Ouidah-Kpomasse-Tori district from Benin (West Africa): A pre-intervention study. Parasit Vectors 2010, 3:83.

9. Carnevale P, Le Goff G, Toto J, VR: Anopheles nili as the main vector of human malaria in villages of southern Cameroon. Med Vet Entomol 1992, 6:135-138.

10. Antonio-Nkondjio C, Awono-Ambene P, Toto JC, Meunier JY, ZebazeKemleu S, Nyambam R, Wondji CS, Tchuinkam T, Fontenill D: High malaria transmission intensity in a village close to Yaounde, the capital city of Cameroon. J Med Entomol 2002, 39:350-355.

11. Prugnolle F, Durand P, Neel C, Ollomo B, Ayala FJ, Arnathau C, Etienne L, Mpoudi-Ngole E, Nkoghe D, Leroy E, et al: African great apes are natural hosts of multiple related malaria species, including Plasmodium falciparum. Proc Natl Acad Sci USA 2010, 107:1458-1463.

12. Duval L, Fourment M, Nerrienet E, Rousset D, Sadeuh SA, Goodman SM, Andriaholinirina NV, Randrianarivelojosia M, Paul RE, Robert $V$, et al: African apes as reservoirs of Plasmodium falciparum and the origin and diversification of the Laverania subgenus. Proceedings of the National Academy of Sciences of the United States of America 2010, 107:10561-10566.

13. Prugnolle F, Ollomo B, Durand P, Yalcindag E, Arnathau C, Elguero E, Berry A, Pourrut X, Gonzalez JP, Nkoghe D, et al: African monkeys are infected by Plasmodium falciparum nonhuman primate-specific strains. Proc Natl Acad Sci USA 2011, 108:11948-11953.

14. Ramirez CA, Requena JM, Puerta CJ: Identification of the HSP70-II gene in Leishmania braziliensis HSP70 locus: genomic organization and UTRs characterization. Parasit Vectors 2011, 4:166.

15. Hiwat H, Bretas G: Ecology of Anopheles darlingi Root with respect to vector importance: a review. Parasit Vectors 2011, 4:177.

16. Cohuet A, Dia I, Simard F, Raymond M, Rousset F, Antonio-Nkondjio C, Awono-Ambene PH, Wondji CS, Fontenille D: Gene flow between chromosomal forms of the malaria vector Anopheles funestus in Cameroon, Central Africa, and its relevance in malaria fighting. Genetics 2005, 169:301-311.

17. Lehmann T, Licht M, Elissa N, Maega BT, Chimumbwa JM, Watsenga FT, Wondji CS, Simard F, Hawley WA: Population structure of Anopheles gambiae in Africa. J Hered 2003, 94:133-147.
18. Gakuya F, Rossi L, Ombui J, Maingi N, Muchemi G, Ogara W, Soriguer RC, Alasaad S: The curse of the prey: Sarcoptes mite molecular analysis reveals potential prey-to-predator parasitic infestation in wild animals from Masai Mara, Kenya. Parasit Vectors 2011, 4:193.

19. Hamarsheh $\mathrm{O}$, Amro A: Characterization of simple sequence repeats (SSRs) from Phlebotomus papatasi (Diptera: Psychodidae) expressed sequence tags (ESTs). Parasit Vectors 2011, 4:189.

20. Alasaad S, Oleaga A, Casais R, Rossi L, Min AM, Soriguer RC, Gortazar C: Temporal stability in the genetic structure of Sarcoptes scabiei under the host-taxon law: empirical evidences from wildlife-derived Sarcoptes mite in Asturias, Spain. Parasit Vectors 2011, 4:151.

21. Melachio TT, Simo G, Ravel S, De Meeus T, Causse S, Solano P, Lutumba P, Asonganyi T, Njiokou F: Population genetics of Glossina palpalis palpalis from central African sleeping sickness foci. Parasit Vectors 2011, 4:140.

22. Ouma JO, Beadell JS, Hyseni C, Okedi LM, Krafsur ES, Aksoy S, Caccone A: Genetic diversity and population structure of Glossina pallidipes in Uganda and western Kenya. Parasit Vectors 2011, 4:122.

23. Kovalenko DA, Razakov SA, Ponirovsky EN, Warburg A, Nasyrova RM, Ponomareva VI, Fatullaeva AA, Nasereddin A, Klement E, Alam MZ, et al: Canine leishmaniosis and its relationship to human visceral leishmaniasis in Eastern Uzbekistan. Parasit Vectors 2011, 4:58

24. Echodu R, Beadell JS, Okedi LM, Hyseni C, Aksoy S, Caccone A: Temporal stability of Glossina fuscipes fuscipes populations in Uganda. Parasit Vectors 2011, 4:19.

25. Hamarsheh O: Distribution of Leishmania major zymodemes in relation to populations of Phlebotomus papatasi sand flies. Parasit Vectors 2011, 4:9.

26. Peacock L, Ferris V, Bailey M, Gibson W: Intraclonal mating occurs during tsetse transmission of Trypanosoma brucei. Parasit Vectors 2009, 2:43.

27. Berthomieu A, Kengne P, Awono-Ambene P, Raymond M, Fontenille D, Weill M: Isolation and characterization of microsatellite DNA markers in the malaria vector Anopheles nili. Molecular Ecology Notes 2003, 3:394-396.

28. Tripet F, Dolo G, Lanzaro GC: Multilevel analyses of genetic differentiation in Anopheles gambiae s.s. reveal patterns of gene flow important for malaria-fighting mosquito projects. Genetics 2005, 169:313-324

29. Lanzaro GC, Toure YT, Carnahan J, Zheng L, Dolo G, Traore S, Petrarca V, Vernick KD, Taylor CE: Complexities in the genetic structure of Anopheles gambiae populations in west Africa as revealed by microsatellite DNA analysis. Proc Natl Acad Sci USA 1998, 95:14260-14265.

30. Ayala D, Fontaine MC, Cohuet A, Fontenille D, Vitalis $R$, Simard F: Chromosomal inversions, natural selection and adaptation in the malaria vector Anopheles funestus. Mol Biol Evol 2011, 28:745-758.

31. Costantini C, Ayala D, Guelbeogo WM, Pombi M, Some CY, Bassole $\mathbb{H}_{\text {, }}$ Ose K, Fotsing JM, Sagnon N, Fontenille D, et al: Living at the edge: biogeographic patterns of habitat segregation conform to speciation by niche expansion in Anopheles gambiae. BMC Ecol 2009, 9:16.

32. Sharakhova MV, Antonio-Nkondjio C, Xia A, Ndo C, Awono-Ambene P Simard F, Sharakhov IV: Cytogenetic map for Anopheles nili: Application for population genetics and comparative physical mapping. Infect Genet Evol 2011, 11:746-754.

33. Coluzzi M, Sabatini A, della Torre A, Di Deco MA, Petrarca V: A polytene chromosome analysis of the Anopheles gambiae species complex. Science 2002, 298:1415-1418.

34. Coluzzi M, Sabatini A, Petrarca V, Di Deco MA: Chromosomal differentiation and adaptation to human environments in the Anopheles gambiae complex. Trans R Soc Trop Med Hyg 1979, 73:483-497.

35. Powell JR, Petrarca V, della Torre A, Caccone A, Coluzzi M: Population structure, speciation, and introgression in the Anopheles gambiae complex. Parassitologia 1999, 41:101-113.

36. Toure YT, Petrarca V, Traore SF, Coulibaly A, Maiga HM, Sankare O, Sow M DiDeco MA, Coluzzi M: The distribution and inversion polymorphism of chromosomally recognized taxa of the Anopheles gambiae complex in Mali, West Africa. Parassitologia 1998, 40:477-511.

37. Simard F, Ayala D, Kamdem GC, Pombi M, Etouna J, Ose K, Fotsing JM, Fontenille D, Besansky NJ, Costantini C: Ecological niche partitioning between Anopheles gambiae molecular forms in Cameroon: the ecological side of speciation. BMC Ecol 2009, 9:17.

38. Gray EM, Rocca KA, Costantini C, Besansky NJ: Inversion 2La is associated with enhanced desiccation resistance in Anopheles gambiae. Malar J 2009, 8:215.

39. Rocca KA, Gray EM, Costantini C, Besansky NJ: 2La chromosomal inversion enhances thermal tolerance of Anopheles gambiae larvae. Malar J 2009, $8: 147$ 
40. Coluzzi M, Sabatini A, Petrarca V, Di Deco MA: Behavioural divergences between mosquitoes with different inversion karyotypes in polymorphic populations of the Anopheles gambiae complex. Nature 1977, 266:832-833.

41. Goltsev Y, Rezende GL, Vranizan K, Lanzaro G, Valle D, Levine M Developmental and evolutionary basis for drought tolerance of the Anopheles gambiae embryo. Dev Biol 2009, 330:462-470.

42. Marinotti O, Nguyen QK, Calvo E, James AA, Ribeiro JMC: Microarray analysis of genes showing variable expression following a blood meal in Anopheles gambiae. Insect Molecular Biology 2005, 14:365-373.

43. Pinto SB, Lombardo F, Koutsos AC, Waterhouse RM, McKay K, An C, Ramakrishnan C, Kafatos FC, Michel K: Discovery of Plasmodium modulators by genome-wide analysis of circulating hemocytes in Anopheles gambiae. Proc Natl Acad Sci USA 2009, 106:21270-21275.

44. Cassone BJ, Mouline K, Hahn MW, White BJ, Pombi M, Simard F, Costantini C, Besansky NJ: Differential gene expression in incipient species of Anopheles gambiae. Mol Ecol 2008, 17:2491-2504.

45. Neira Oviedo M, Vanekeris L, Corena-McLeod MD, Linser PJ: A microarraybased analysis of transcriptional compartmentalization in the alimentary canal of Anopheles gambiae (Diptera: Culicidae) larvae. Insect Mol Biol 2008, 17:61-72.

46. Neira Oviedo M, Ribeiro JM, Heyland A, VanEkeris L, Moroz T, Linser PJ: The salivary transcriptome of Anopheles gambiae (Diptera: Culicidae) larvae: A microarray-based analysis. Insect Biochem Mol Biol 2009, 39:382-394.

47. Rogers DW, Baldini F, Battaglia F, Panico M, Dell A, Morris HR, Catteruccia F: Transglutaminase-mediated semen coagulation controls sperm storage in the malaria mosquito. PLOS Biol 2009, 7:e1000272.

48. Kamali M, Sharakhova M, Baricheva E, Karagodin D, Tu Z, Sharakhov IV: An integrated chromosome map of microsatellite markers and inversion breakpoints for an Asian malaria mosquito, Anopheles stephensi. Journal of Heredity 2011.

49. Sharakhov I, Braginets O, Grushko O, Cohuet A, Guelbeogo WM, Boccolini D, Weill M, Costantini C, Sagnon N, Fontenille D, et al: A microsatellite map of the African human malaria vector Anopheles funestus. J Hered 2004, 95:29-34.

50. Michel AP, Guelbeogo WM, Grushko O, Schemerhorn BJ, Kern M, Willard MB, Sagnon N, Costantini C, Besansky NJ: Molecular differentiation between chromosomally defined incipient species of Anopheles funestus. Insect Mol Biol 2005, 14:375-387.

51. Gillies MT, Coetzee M: A supplement to the Anophelinae of Africa south of the Sahara. Pub/ S Afr Inst Med Res 1987, 55:1-143.

52. Awono-Ambene HP, Kengne P, Simard F, Antonio-Nkondjio C, Fontenille D: Description and bionomics of Anopheles (Cellia) ovengensis (Diptera: Culicidae), a new malaria vector species of the Anopheles nili group from south Cameroon. J Med Entomol 2004, 41:561-568.

53. Brunhes J, Cuisance D, Cuny G, Manguin S, de La Rocque S, Geoffrey B: Medical entomology: the technological explosion. Med Trop (Mars) 1998, 58:15-20.

54. Kengne P, Awono-Ambene P, Antonio-Nkondjio C, Simard F, Fontenille D: Molecular identification of the Anopheles nili group of African malaria vectors. Med Vet Entomol 2003, 17:67-74.

55. Lawson D, Arensburger P, Atkinson P, Besansky NJ, Bruggner RV, Butler R, Campbell KS, Christophides GK, Christley S, Dialynas E, et al: VectorBase: a data resource for invertebrate vector genomics. Nucleic Acids Res 2009, 37:D583-587.

56. Rozen S, Skaletsky H: Primer3 on the www for general users and for biologist programmers. Methods Mol Biol 2000, 132:365-386.

57. Demin S, Pleskach N, Svetlova M, Solovjeva L: High-resolution mapping of interstitial telomeric repeats in Syrian hamster metaphase chromosomes. Cytogenet Genome Res 2011, 132:151-155.

58. Rousset F: GENEPOP ' 007: a complete re-implementation of the GENEPOP software for Windows and Linux. Molecular Ecology Resources 2008, 8:103-106.

59. Weir BS, Cockerham CC: Estimating F-Statistics for the Analysis of Population-Structure. Evolution 1984, 38:1358-1370.

doi:10.1186/1756-3305-4-202

Cite this article as: Peery et al: Improving the population genetics toolbox for the study of the African malaria vector Anopheles nili: microsatellite mapping to chromosomes. Parasites \& Vectors 2011 4:202.

\section{Submit your next manuscript to BioMed Central and take full advantage of:}

- Convenient online submission

- Thorough peer review

- No space constraints or color figure charges

- Immediate publication on acceptance

- Inclusion in PubMed, CAS, Scopus and Google Scholar

- Research which is freely available for redistribution 